\title{
Nanotechnology and global energy demand: challenges and prospects for a paradigm shift in the oil and gas industry
}

\author{
Richard O. Afolabi ${ }^{1}$ (D) Esther O. Yusuf ${ }^{2}$
}

Received: 27 April 2018 / Accepted: 20 August 2018 / Published online: 24 August 2018

(c) The Author(s) 2018

\begin{abstract}
The exploitation of new hydrocarbon discoveries in meeting the present global energy demand is a function of the availability and application of new technologies. The relevance of new technologies is borne out of the complex subsurface architecture and conditions of offshore petroleum plays. Conventional techniques, from drilling to production, for exploiting these discoveries may require adaption for such subsurface conditions as they fail under conditions of high pressure and high temperature. The oil and gas industry over the past decades has witnessed increased research into the use of nanotechnology with great promise for drilling operations, enhanced oil recovery, reservoir characterization, production, etc. The prospect for a paradigm shift towards the application of nanotechnology in the oil and gas industry is constrained by evolving challenges with its progression. This paper gave a review of developments from nano-research in the oil and gas industry, challenges and recommendations.
\end{abstract}

Keywords Nanotechnology $\cdot$ Energy demand $\cdot$ Production $\cdot$ Oil and gas industry

\section{Introduction}

Demand for petroleum-based products has increased over the years with global industrialization and population (William et al. 2014). Unfortunately, existing oil and gas fields are matured with production in the declining phase (William et al. 2014). New oil field discoveries have been reported in complex reservoir environments, which are mostly under high pressure and high temperature (HPHT) (Mahmoud et al. 2016; Afolabi et al. 2017b). The future of the global oil and gas industry would depend largely on the development of new technologies in other to meet growing energy demand. Consequently, new technologies are required across the petroleum value chain, i.e. exploration (frontier exploration and basin exploitation), appraisal, field development, production, reserves growth and field reactivation or abandonment (Abdo and Danish Haneef 2012; Hoelscher et al. 2012; Ismail et al. 2016a, b; Afolabi et al. 2017a, b). Recent

Richard O. Afolabi

richard.afolabi@covenantuniversity.edu.ng

1 Department of Petroleum Engineering, Covenant University, P.M.B 1023, Ota, Ogun State, Nigeria

2 Department of Chemical Engineering, Covenant University, P.M.B 1023, Ota, Ogun State, Nigeria research trend have shifted in various disciplines from the "Macro-domain" to the "Micro-domain" and "Nanodomain" and probably in the coming years to "Pico-domain" and "Femto-domain". Already there is a talk of "Picotechnology" where matter is handled at the atomic scale. Picoparticles are considered as clusters of atoms. Although considered by futurist as hypothetical, there have been reports of the synthesis and use of gold picoparticles for catalysis. "Femtotechnology", on the other hand, deals with the handling of agitated energy levels inside atomic cores, which would result in metastable conditions with rare attributes. "Femtotechnology" for now has no practical application and it has been considered hypothetical by futuristic scientists and engineers. In other words, the summary of all this is that technological advancement in the world today is achieved through scaling down. Furthermore, areas such as microfluidics, nanofluidics, nanoscience, and nanotechnology have witnessed increased research due to the advancing trend of scaling down in technological innovations. Nanoparticles are considered to be engineered to have at least a dimension in the order of $100 \mathrm{~nm}$. The uniqueness of nanoparticles is tied to its size-dependent properties, which are a consequence of its large surface to volume ratio, thereby enabling surface atoms/molecules to have a significant impact on its properties (Bennetzen and Mogensen 2014; Gerogiorgis et al. 
2017). Furthermore, due to the small size of nanoparticles, the amount of surface atoms is large compared to the bulk atoms. This enables the properties of nanoparticles to be governed by the surface atoms and can be described by the physics of quantum mechanical consideration (Bennetzen and Mogensen 2014). In addition, the high surface to volume ratio of nanoparticles ensures that considerable amount of free surface energy exists within them (Zakaria et al. 2012; Bennetzen and Mogensen 2014; Vryzas and Kelessidis 2017). This explains the strong force of attraction that exists between nanoparticles when in suspension. The attraction between nanoparticles or to other molecules ensures that the free energy is minimized. Nanoparticles can be tailormade to meet specific application depending on the property of interest (Vryzas and Kelessidis 2017). The desired properties can include thermal, mechanical, chemical, electrical, optical, magnetic, etc. The shift in the discovery of petroleum plays to difficult offshore locations has made the thermal and mechanical properties of tailor-made nanoparticles ideal for such environment (Wen et al. 2009; Bennetzen and Mogensen 2014; Vryzas and Kelessidis 2017). Research into the use of nanoparticles in the global oil and gas industry cuts across every aspect of the industry such as drilling mud preparation, corrosion and erosion control, exploration, and oil recovery. The application of nanoparticles, for example, in the formulation of water-based drilling muds have improved their performance in reducing fluid loss when applied in shale formations as a result of their sizedependent properties (Hoelscher et al. 2012; Zakaria et al. 2012; Jung et al. 2013; Sadeghalvaad and Sabbaghi 2015). Despite the promising results obtained from laboratory studies, there has not been any reported large-scale field application of nanotechnology in the oil and gas industry except for some small-scale field trials. In this paper, a detailed review of the developments from nano-research in the petroleum industry and its attendant challenges are presented.

\section{Application of nanotechnology in the oil and gas industry}

\section{Nanotechnology and oil recovery process}

Renewable energy sources such as crude oil, in meeting energy needs, are function of new hydrocarbon discoveries and improving the recovery of existing oil fields. However, new crude oil discoveries are made at a decreasing rate likewise existing fields are at a declining phase with conventional recovery techniques not being able to produce as much as two thirds of the oil in place. In complementing existing oil recovery techniques, research into the use of nanotechnology has emerged as a potential alternative for tertiary oil recovery scheme. "Nano-EOR" is a term used in describing the use of nanoparticles for enhanced oil recovery (EOR) process. The mechanism by which nanoparticles improve the recovery of residual oil has been established via wettability alteration and interfacial tension reduction. The combination of these two may not be the only underlying mechanism as several other approach have been offered for nano-EOR "Nano-EOR" is a term used in describing the use of nanoparticles for EOR process. While there is a limited report on field application of this technique for EOR, research has shown that it is a promising route in improving the recovery of residual oil in meeting the ever-growing societal demand for it. This segment of the review would look at the current state of art with respect to nano-EOR in two parts. The first part would focus on the underlying mechanism by which nanoparticles improve oil recovery. The second part would look at the propagation of nanoparticles during the nanoEOR process.

\section{Wettability and interfacial tension alteration using nanoparticles}

Residual oil saturation exists in reservoirs due to "oil entrapment" at the microscopic level arising from capillary forces and "oil bypass" at the macroscopic level during secondary recovery (Bennetzen and Mogensen 2014). An approach to improving or enhancing the recovery of oil from rock formations would be the alteration of the wettability of such formations (Miranda et al. 2012; Ogolo et al. 2012; Roustaei et al. 2012; ShamsiJazeyi et al. 2014). A formation is said to be water wet if the angle of contact on the surface of the rock is below $90^{\circ}$ while it is said to be oil wet if the angle of contact on the surface of the rock is greater than $90^{\circ}$. A water wet formation would have oil easily extracted from it than an oilwet formation (Ogolo et al. 2012; ShamsiJazeyi et al. 2014). The use of nanoparticles in improving oil recovery has been reported in several literatures. Son et al. (2014) investigated the use of nanoparticle stabilized oil/water emulsions as EOR agents in a column of silica bead having mineral oil. The result showed an increase in the rate of oil recovery of about $11 \%$ after water flooding. This can be ascribed to larger pressure variance through the column, which enables the remaining oil in it to be produced through a piston effect. Ogolo et al. (2012) carried out a comparative study on the effect of eight different nanoparticle oxides (oxides of magnesium, zinc, aluminium, silicon, tin, nickel, zirconium, and iron) on oil recovery under surface conditions. The dispersion media used in preparing the nanofluids include water, ethanol, diesel, and brine. The experimental results from the study showed that the oxides of aluminium and silicon would be suitable for EOR application when they are dispersed in water and brine. In the case of ethanol being the dispersion media, it was discovered that silane-treated oxide of silicon gave the most oil recovery. It was also discovered from the experiment that the oxide of 
aluminium reduces the viscosity of oil while that of silicon alters the wettability of rock as well reducing the interfacial tension between oil and water. The phenomenon of wettability modification and interfacial energy decrease is widely seen as the mechanism through which nanoparticles work in enhancing the recovery of oil from oil-bearing formations (Onyekonwu and Ogolo 2010; Ogolo et al. 2012; Roustaei et al. 2012; ShamsiJazeyi et al. 2014). Onyekonwu and Ogolo (2010) looked at the ability of polysilicon nanoparticles which are hydrophilic and lipophilic (LHPN), polysilicon nanoparticles which are hydrophobic and lipophilic (HLPN), and polysilicon nanoparticles which are neutrally wet (NWPN) on improving oil recovery through wettability alteration. The experimental results obtained from the study indicates that HLPN and NWPN improved oil recovery in water wet formations and the mechanism through with this was achieved was through wettability alteration and interfacial tension reduction when the dispersion medium for the nanoparticles is ethanol. The LHPN was observed to increase oil recovery in oil formations that are water wet. In addition, buttressing the phenomenon of wettability modification and interfacial energy decline of nanoparticles was the work of Roustaei et al. (2013). They evaluated and related the effectiveness of modified silica nanoparticles in improving the recovery of oil from two oil reservoirs: light Iranian and intermediate oil reservoirs. Results from their experimental study showed that in the presence of silica nanoparticles, there was a reduction in the interfacial tension in the case of light and intermediate oil. Furthermore, contact angle measurement showed that there was an alteration of wettability of rock from oil-wet condition to water-wet condition. They explained that the presence of the nanoparticles in aqueous solutions in porous media improved the recovery of oil through the reduction of interfacial energy and modification of wettability from oil wet to water wet. Trapped oil droplets in the porous media are mobilized through interfacial tension reduction (Fig. 1). In addition, the role of capillary pressure was changed from being a barrier force to a driving force through wettability alteration. One of the associated challenges with the use of nanoparticles is the determination of the optimal amount of nanofluid for addition to a reservoir. Although the study of nanoparticles as wettability modifiers is still relatively new with no clear-cut explanation to the mechanism of wettability alteration, it is important to point out that the concentration of nanoparticles in solution may affect the rock wettability through rock-fluid interaction. Roustaei and Barzagadeh (2015) investigated the effect of nanoparticle concentration in aqueous solution on the wettability of carbonate rocks with the sole purpose of determining the optimal amount of nanofluid for addition to core samples. Their result indicates that a concentration of $4 \mathrm{~g} / \mathrm{dL}$ was the optimum concentration of nanofluid that would significantly alter the wettability of the surface of the rock from oil wet to water wet. A rock surface is either water wet or oil wet based on the surface energy and interfacial energy (ShamsiJazeyi et al. 2014). The spreading coefficient of water, $S$, on the surface of a solid that is oil wet and in communication with water and oil can be related to the interfacial tension between each phase by the following expression:

$S_{\mathrm{W}}=\gamma_{\mathrm{O} / \mathrm{S}}-\gamma_{\mathrm{W} / \mathrm{S}}-\gamma_{\mathrm{O} / \mathrm{W}}$,

where $S_{\mathrm{W}}$ is the spreading coefficient of water on the solid surface, $\gamma_{\mathrm{O} / \mathrm{S}}$ is the interfacial energy between oil and solid, $\gamma_{\mathrm{W} / \mathrm{S}}$ is the interfacial tension between water and solid, and $\gamma_{\mathrm{O} / \mathrm{W}}$ is the interfacial tension between oil and water. In

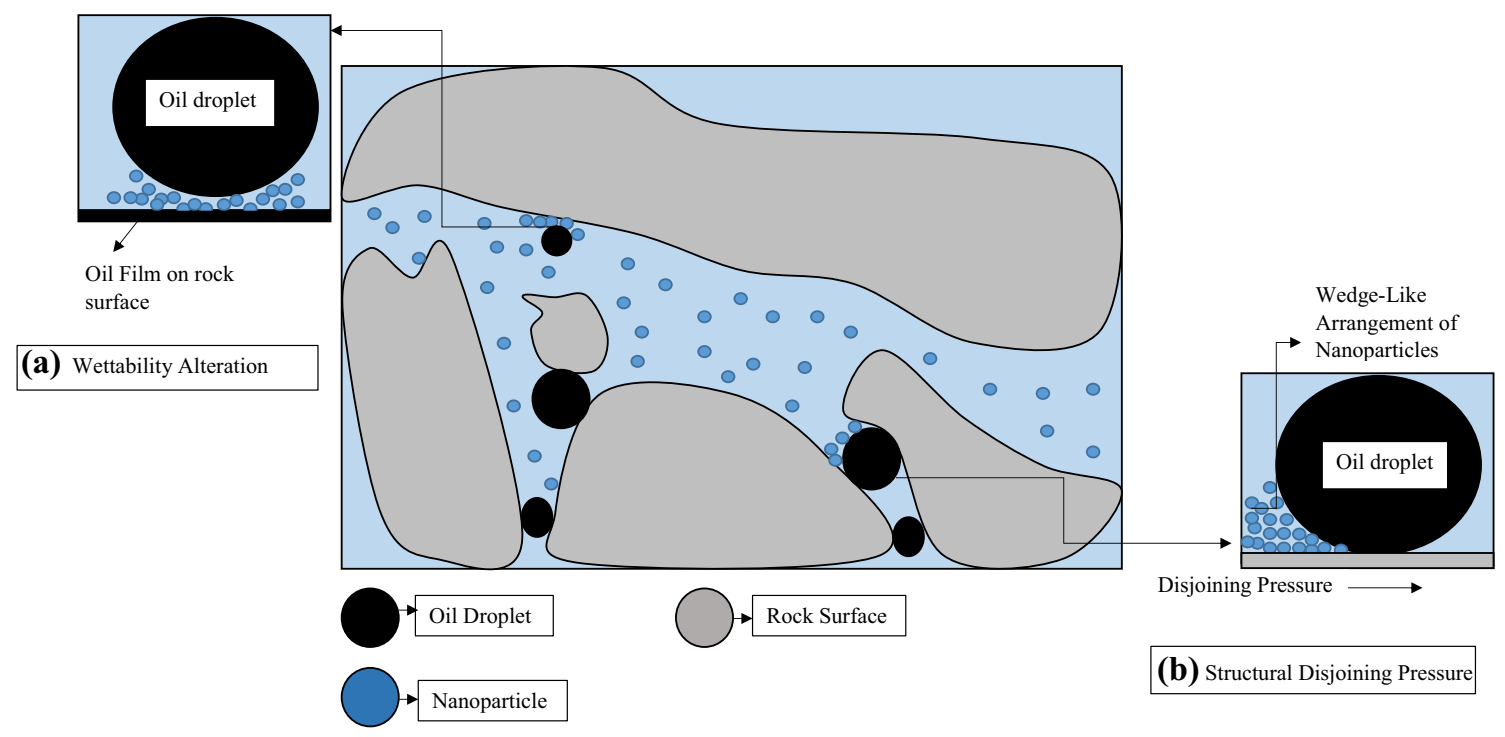

Fig. 1 Mechanism of nanoparticle-enhanced oil recovery (Nano-EOR). a Wettability alteration by nanoparticles and $\mathbf{b}$ structural joining pressure by nanoparticles 
Eq. (1), when the interfacial tension between oil and water is reduced, the spreading coefficient of water increases, thereby making the surface more water wet. In addition, if the interfacial tension $\gamma_{\mathrm{W} / \mathrm{S}}$ and $\gamma_{\mathrm{O} / \mathrm{W}}$ is both reduced, the rock also becomes more water wet. The spreading of water and contact angle reduction is due to a force balance between adhesion and cohesion. Force of adhesion exists between the molecules of water and the rock surface while the force of cohesion exists between the molecules of water. When interfacial tension between oil and water, water and solid is reduced, the force of adhesion between water molecules and the rock surface becomes more pronounced, thereby increasing the spreading coefficient of water and making the rock more water wet. The spreading coefficient of oil, $S_{0}$, on the surface of a solid which is water wet and in communication with water and oil can also be related to the interfacial tension between each phase by the following expression:

$S_{\mathrm{o}}=\gamma_{\mathrm{W} / \mathrm{S}}-\gamma_{\mathrm{O} / \mathrm{S}}-\gamma_{\mathrm{O} / \mathrm{W}}$

where $S_{\mathrm{o}}$ is the spreading coefficient of oil on the solid surface, $\gamma_{\mathrm{O} / \mathrm{S}}$ is the interfacial energy amongst oil and solid, $\gamma_{\mathrm{W} / \mathrm{S}}$ stands for the interfacial tension amongst water and solid, and $\gamma_{\mathrm{O} / \mathrm{W}}$ denotes the interfacial energy among oil and water. In Eq. (2), when the interfacial tension between oil and water is reduced, the spreading coefficient of oil increases, thereby making the surface more oil wet. In addition, if the interfacial tension $\gamma_{\mathrm{O} / \mathrm{S}}$ and $\gamma_{\mathrm{O} / \mathrm{W}}$ are both reduced, the rock also becomes more oil wet. The spreading of oil and contact angle increment is due to a force balance between adhesion and cohesion. Force of adhesion exists between the molecules of oil and the rock surface while the force of cohesion exists between the molecules of oil. When interfacial tension between oil and water, oil and solid is reduced, the force of adhesion between oil molecules and the rock surface becomes more pronounced, thereby increasing the spreading coefficient of oil and making the rock more oil wet. However, the mechanism of wettability alteration for nanofluids is still in its infancy and many kinds of literature have reported different approaches (Roustaei and Barzagadeh 2015; ShamsiJazeyi et al. 2014), but wettability alteration for nanoparticles is always from oil wet to water wet. Another literature, report on wettability modification involving the use of surfactants and nanofluid mixtures (ShamsiJazeyi et al. 2014). Furthermore, such study did not provide conclusive evidence on the impact of nanoparticles on wettability alteration, as surfactants are already known wettability modifiers. Fluid-rock interactions and fluid-fluid interactions may also explain how nanofluid affects wettability alteration. Sandstone formations are mainly made up of minerals of silica whose charges are negative at neutral $\mathrm{pH}$ while dolomite is mainly positively charged due to its large content of calcium and magnesium ions (Yu et al. 2010). When nanofluid made up of positively charged nanoparticles flows in a porous sandstone media, which is oil wet, some of the nanoparticles may adsorb on the rock surface while others may adhere to the oil-water interface. A plausible explanation for the fluid-rock interaction could be that when nanoparticles in the nanofluid come in contact with the charged sandstone rock surface, charge interaction between the nanoparticle and rock allows the nanoparticles to be adhered to the rock surface. This disrupts whatever molecular attachment amongst the rock surface and the oil molecules accountable for the oil-wet condition. A rock surface initially water wet could become oil wet if it is exposed to oil for some time. During this exposure period, it can be deduced that a dipole-dipole attraction could have resulted between the rock surface and the oil molecules allowing for oil-wet conditions. The charged rock surface can temporarily cause an uneven charge distribution in a non-polar oil molecule allowing temporary charges to build upon the oil molecules. For example, a positively charged carbonate rock if exposed to oil, which is non-polar for a certain period, can attain dipoles due to the attraction of electrons in the oil molecules towards the positively charged carbonate rock. This allows oil-wet condition to be attained with the carbonate rock. The same phenomenon can be attributed to nanofluids containing nanoparticles when they interact with the charged surface. The charged rock surface can temporarily cause an uneven charge distribution in the nanofluid allowing temporary charges to build up. The charged nanoparticles on the rock surface can form hydrogen bonds with water molecules, thereby attracting water molecules on the rock surface. This reduces the interfacial tension between rock surface and water, $\gamma_{\mathrm{W} / \mathrm{s}}$ and allows water-wet condition to be created on the rock surface. At the water-oil interface, the nanoparticles form hydrogen bond with the water molecules, thereby increasing the interfacial tension between the oil and water, $\gamma_{\mathrm{O} / \mathrm{w}}$. This increase in interfacial tension between oil and water allows for greater capillary pressure, which will ensure a greater imbibition of water into lesser pores of the rock and hence improved oil recovery (Roustaei and Barzagadeh 2015).

\section{Disjoining pressure due to nanoparticles}

It is observed that when a solution of nanofluid encounters an oil droplet on a solid surface, two contact lines arise (ShamsiJazeyi et al. 2014). These lines are separated by a layer of well-ordered nanoparticle structures, which brings about high disjoining pressures, thereby causing the wedgelike spreading of the nanoparticles before the inner line and after the outer line (Fig. 1). The generation of this wellordered wedge-like structure of nanoparticles is driven by the injection pressure of the nanofluids, thereby forcing the nanoparticles into a confined region (Sun et al. 2017). This arrangement increases the entropy of the nanofluids due to 
the greater freedom of the NPs in the nanofluids, thereby resulting in the exertion of a disjoining pressure. The identified forces behind the structural disjoining pressure include van der Waals, Brownian motion and electrostatic repulsion. The electrostatic repulsion between the nanoparticles will be higher due to their small size, thereby giving a larger structural disjoining pressure. The disjoining pressure arises due to the ability of nanoparticle dispersions to interact with the rock surface, thereby causing an imbalance in the interfacial forces between the oil and the solid phases. The magnitude of the disjoining force arising from the nanoparticle dispersions depends on nanoparticle parameters (size, volume fraction and stability), rock properties, salinity and temperature. The presence of salts and electrolytes would reduce the repulsive force between nanoparticles leading to aggregation or agglomeration. Nanoparticle aggregates would reduce the structural disjoining pressure as ordering of particles inside the wedge structure would not occur due to a reduction in the overall entropy of the system. Nanoparticle in the dispersed medium achieves lesser freedom at this state of aggregation.

\section{Propagation of nanoparticles in porous media}

Most oilfield environments are made up of high temperature, salinity, pressure and rock property distribution is not uniform in nature (Yu et al. 2010; Miranda et al. 2012; ShamsiJazeyi et al. 2014). The understanding of the propagation and adsorption of nanoparticles is crucial in their use in such environment. ShamsiJazeyi et al. (2014) cited three mechanisms which affect the transmission of nanoparticles in a media which is porous and this includes filtration through a physical process, chemical stability in solution and adsorption on the surface of a medium which is porous. Physical filtration is connected with particle size being larger than pore size in porous media and it is independent of nanoparticle dispersibility (ShamsiJazeyi et al. 2014). It depends on the shape, size distribution and aspect ratio of nanoparticles. Nanoparticle aggregation occurs because of hydrophobic and van der Waals interactions that can be inhibited through polymer coatings on it. The chemical solution stability of nanoparticles is affected by salinity and the presence of divalent ions. Miranda et al. (2012) studied the stability and mobility of functionalized silica nanoparticles at high salt concentration and temperature for EOR purposes. They discovered that the presence of ions can modify the transport behavior of nanoparticles. This was observed through an increase in the coefficients of diffusion for nanoparticles with increasing amount of salt. In addition, nanoparticle adsorption on the exterior of rocks and the presence of salt solutions tend to impact on interfacial tension through modification of electrostatic potential and hydration characteristics of the salt ions near the nanoparticle surface (Miranda et al. 2012) (Table 1).
Yu et al. (2010) investigated the essential carriage and retaining properties of nanoparticles under extreme salinity by means of real core supplies. The stability of the nanoparticles was found to be reliant on the amount of communication amongst nanoparticles, a solution containing salt ions and exterior of the porous medium, which affects retention and retardation. The presence of divalent ions may affect the propagation of nanoparticles through the formation of "salt-bridge" between the ions and the nanoparticle (Ogolo et al. 2012). Retention of nanoparticles on the exterior of rocks is as a result of charge communication amongst the nanoparticles and the exterior of the rock. Carbon nanoparticles, which are essentially negatively charge, were discovered not to be retained on sandstone mineral during a transport study of carbon nanoparticles (Ogolo et al. 2012). This may be due to electrostatic force of repulsion amongst the sandstone minerals, which are charged negatively, and the negatively stimulated carbon nanoparticles. Nanoparticles, which have polymers covalently attached to its surface, are known as polymer-coated nanoparticles (PNPs). PNPs can be seen as nanoparticles whose surface has been functionalized or modified with polymer materials (Subbiah et al. 2010). While some polymeric coatings can stabilize nanoparticles, they cannot prevent their adsorption on rock surfaces. The strength of nanoparticles with coatings of polyelectrolyte is also affected by the increase in salinity and $\mathrm{pH}$. The use of elongated polymer chains such as starch, polyacrylamide or cellulose as covering on a nanoparticle surface to make them stable in solution has not been successful at high salinities in most reservoirs because of poor solubility of the polymers. PNPs have been shown to behave in a different way under static and dynamic conditions. ShamsiJazeyi et al. (2014) also mentioned the behavior of solutions of iron nanoparticles coated with poly (acrylic acid) and its transport along a porous media. It was discovered that nanoparticle size depends on the number of nanoparticles under dynamic conditions and not static. It was concluded that the forces acting on nanoparticles under dynamic conditions are absent under static conditions. This reflects how complex the effects of flow rate, permeability, etc., on nanoparticles under dynamic conditions and using static conditions to validate the chemical stability of nanoparticles may not be sufficient. The propagation of well-stabilized functionalized nanoparticles in porous media may be hindered and retarded by adsorption on the rock surface (Yu et al. 2010; ShamsiJazeyi et al. 2014). PNPs, which have a charged surface, which is the same as the rock surface or less hydrophobic, may show less adsorption. This can be challenging given the salinities and divalent ion concentration present in most oil reservoirs. Table 2 shows a summary of some experimental works done on nano-EOR.

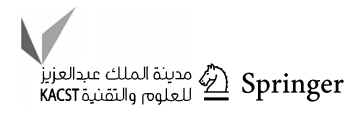


Table 1 Summary on experimental studies about wettability alteration by nanofluids (copyright: Sun et al. 2017)

\begin{tabular}{|c|c|c|c|c|c|c|c|}
\hline \multirow[t]{2}{*}{ References } & \multirow[t]{2}{*}{ NPs/base fluids } & \multirow[t]{2}{*}{ Oil type } & \multicolumn{2}{|l|}{ Oil properties } & \multirow[t]{2}{*}{ Rock type } & \multirow{2}{*}{$\begin{array}{l}\text { Measurement } \\
\text { methods }\end{array}$} & \multirow[t]{2}{*}{ Influence factors } \\
\hline & & & Density $\left(\mathrm{kg} / \mathrm{m}^{3}\right)$ & Viscosity (cp) & & & \\
\hline $\begin{array}{l}\text { Al-Anssari et al. } \\
\text { (2016) }\end{array}$ & $\mathrm{SiO}_{2} /$ brine & $N$-Decane & N/A & N/A & Calcite & $\begin{array}{l}\text { Contact angle } \\
\text { method }\end{array}$ & $\begin{array}{l}\text { NP concentration, } \\
\text { salinity, time, and } \\
\text { reversibility of NP } \\
\text { adsorption }\end{array}$ \\
\hline Li et al. (2013) & $\mathrm{SiO}_{2} /$ brine & Light oil & 826 & 5.1 & Glass & $\begin{array}{l}\text { Contact angle } \\
\text { method }\end{array}$ & NP concentration \\
\hline $\begin{array}{l}\text { Giraldo et al. } \\
\text { (2013) }\end{array}$ & $\begin{array}{l}\mathrm{Al}_{2} \mathrm{O}_{3} / \text { anionic sur- } \\
\text { factant solution }\end{array}$ & Heavy oil & 895 & 64 & Sandstone & $\begin{array}{l}\text { Contact angle } \\
\text { method, Amott } \\
\text { test and core dis- } \\
\text { placement test }\end{array}$ & NP concentration \\
\hline Li et al. (2015) & $\mathrm{SiO}_{2} /$ brine & Light oil & 847 & 15.3 & Sandstone & Amott test & $\begin{array}{l}\text { NP type and con- } \\
\text { centration }\end{array}$ \\
\hline $\begin{array}{l}\text { Roustaei and Bagh- } \\
\text { erzadeh (2015) }\end{array}$ & $\mathrm{SiO}_{2} /$ brine & Light oil & 857 & 11 & Carbonate & $\begin{array}{l}\text { Contact angle } \\
\text { method }\end{array}$ & NP concentration \\
\hline $\begin{array}{l}\text { Mohebiffar et al. } \\
\text { (2015) }\end{array}$ & $\begin{array}{l}\mathrm{SiO}_{2} \text {-biometrical/ } \\
\text { water }\end{array}$ & Heavy oil & 925 & 200 & Shale & $\begin{array}{l}\text { Contact angle } \\
\text { method }\end{array}$ & NP concentration \\
\hline $\begin{array}{l}\text { Maghzi et al. } \\
\text { (2012) }\end{array}$ & $\mathrm{SiO}_{2} /$ brine & Heavy oil & 933 & 870 & Glass & $\begin{array}{l}\text { Contact angle } \\
\text { method }\end{array}$ & NP concentration \\
\hline $\begin{array}{l}\text { Hendraningrat and } \\
\text { Torsæter (2014) }\end{array}$ & $\begin{array}{l}\left(\mathrm{SiO}_{2}, \mathrm{Al}_{2} \mathrm{O}_{3},\right. \\
\left.\mathrm{TiO}_{2}\right)+ \text { povidone/ } \\
\text { brine }\end{array}$ & Light oil & 826 & 5.1 & Quartz & $\begin{array}{l}\text { Contact angle } \\
\text { method }\end{array}$ & NP type \\
\hline Karimi et al. (2012) & $\begin{array}{c}\mathrm{ZrO}_{2}+\text { surfactants/ } \\
\text { distilled water }\end{array}$ & Heavy oil & 861 & 425 & Carbonate & $\begin{array}{l}\text { Contact angle } \\
\text { method, Amott } \\
\text { test }\end{array}$ & $\begin{array}{l}\text { Aging time, type } \\
\text { of nonionic sur- } \\
\text { factants and }\end{array}$ \\
\hline $\begin{array}{l}\text { Hendraningrat et al. } \\
\text { (2013) }\end{array}$ & $\mathrm{SiO}_{2} /$ brine & Light oil & 826 & 5.1 & Sandstone & $\begin{array}{l}\text { Contact angle } \\
\text { method, Amott } \\
\text { test }\end{array}$ & NP size \\
\hline
\end{tabular}

\section{Mechanical entrapment and log jamming}

The phenomenon of mechanical entrapment by nanoparticles occurs when the size of the particles is larger than the pore size or pore throat of the reservoir formation (Fig. 2). Log jamming by nanoparticles occurs due to the accumulation of nanoparticles at the pore throat larger than the size of the nanoparticles. The accumulation of the nanoparticles at the pore throat creates additional pressure in the adjacent pore throat, thereby forcing out trapped oil droplets in the pores (Sun et al. 2017). Nanoparticle accumulation takes place when nanoparticle velocity is less than that of the carrying fluid during flow from the pore to the throat. The constriction in the flow area between the pore and the throat creates increase in the velocity of the nanoparticle dispersion with water flowing faster than the nanoparticles (Sun et al. 2017). This allows for nanoparticle accumulation in the pore throat.

\section{Controlling the viscosity of injected fluids}

The viscosity of injected fluids for oil recovery is affected by the concentration of the nanoparticles employed (ShamsiJazeyi et al. 2014). The increase in the viscosity of the injected fluid due to nanoparticle can be explained in terms of a reduction in the mobility of adjacent fluid molecules around the nanoparticles. The size of the nanoparticles also affects the shear viscosity of the injected fluids. Increase in the size of the nanoparticles leads to an increase in the viscosity of the injected fluids (Shah 2009). An important parameter for monitoring the mobility of the injected fluid is the "Mobility Factor". The Mobility factor, $M$, is defined as the ratio of the mobility of the displacing fluid to that of the displaced fluid. This is represented mathematically in the following equation:

$M=\frac{\lambda_{\mathrm{i}}}{\lambda_{\mathrm{o}}}$,

where $\lambda_{\mathrm{i}}$ and $\lambda_{\mathrm{o}}$ are the mobilities of the injected fluid and oil, respectively. When the mobility ratio $M \leq 1$, the mobility of the injected fluid is less than or equal to the mobility of the displaced oil $\left(\lambda_{\mathrm{i}} \leq \lambda_{\mathrm{o}}\right)$. This occurs with an increase in the concentration or size of the nanoparticle in the injected fluids. The consequence of this is an even displacement front and a reduction in the incidence of viscous fingering and early water breakthrough (Fig. 3). When the mobility ratio 


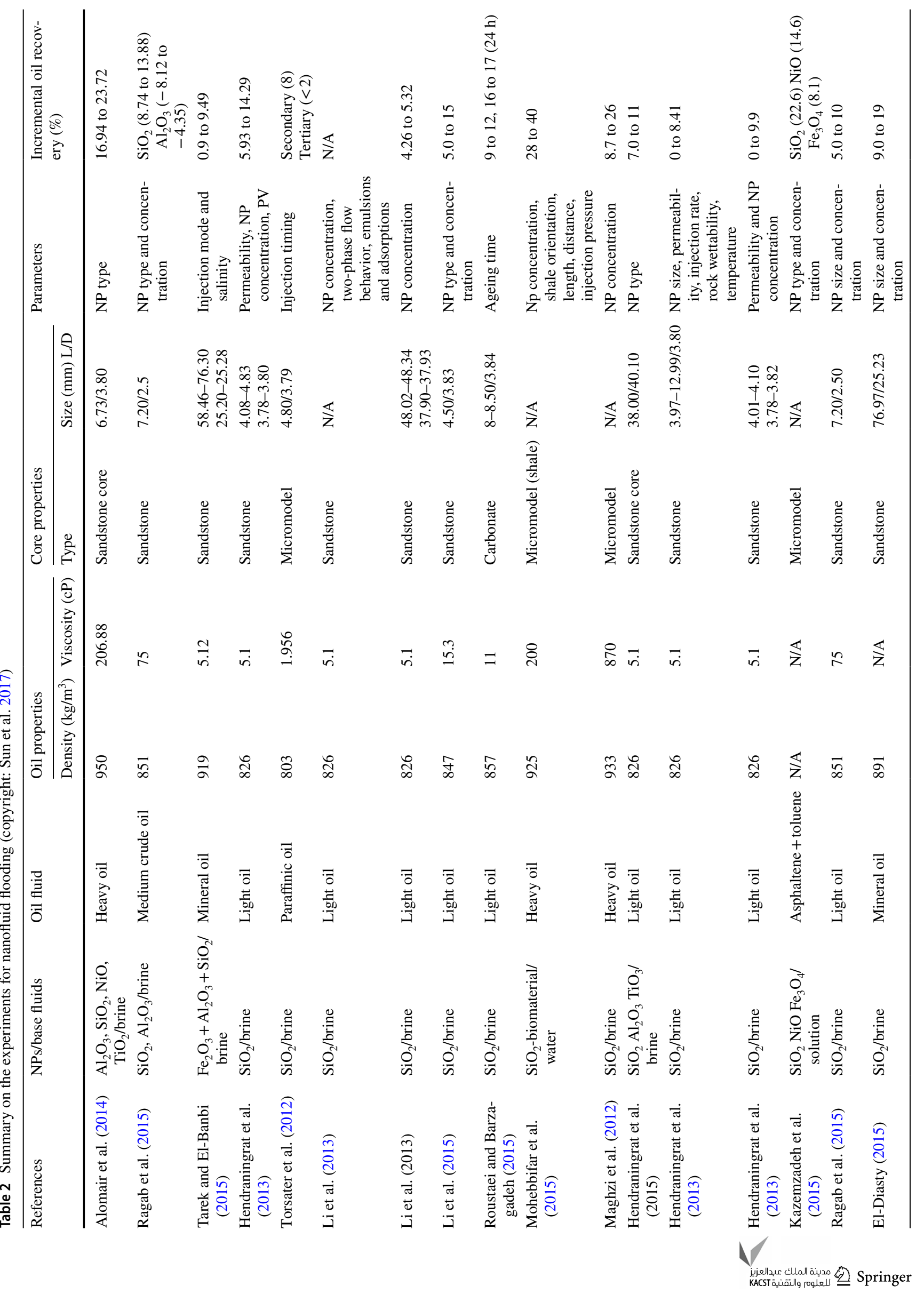




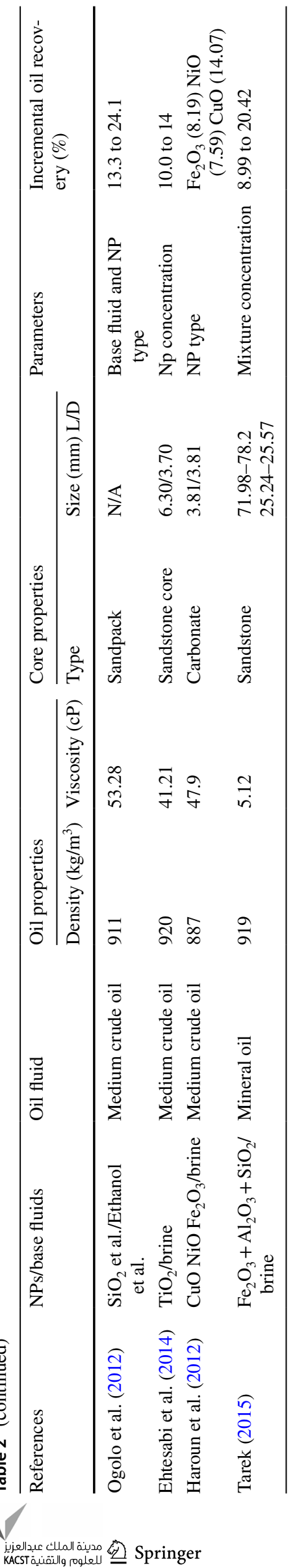

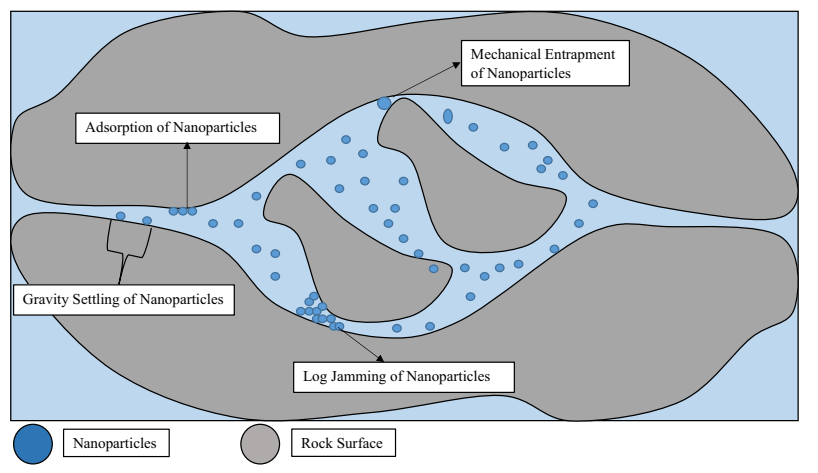

Fig. 2 Different retention mechanisms of nanoparticles in porous media

$M>1$, the mobility of the injected fluid is greater than the mobility of the displaced oil $\left(\lambda_{\mathrm{i}}>\lambda_{\mathrm{o}}\right)$. This occurs with a decrease in the concentration or size of the nanoparticle in the injected fluids.

\section{Nanotechnology and drilling operations}

Drilling fluid properties such as wellbore and shale stabilization, cuttings suspensions, magnetic properties, wellbore strengthening, fluid loss, rheology and thermal properties, etc., are readily modifiable by the addition of various types of nanoparticles. The promising results obtained from experimental studies on the use of nanoparticles in drilling fluids show that they could be applied to overcome difficult drilling challenges faced in the petroleum industry. Nonetheless, challenges still exist which must be overcome in order for nanoparticles to be fully applied in the industry.

\section{Rheology and fluid loss: impact of nanoparticles}

Ensuring that the rheological properties of drilling fluids are controlled and monitored remains an important aspect of successful drilling operations. Pressure loss prediction, for example, is mainly a function of the precise knowledge of the rheology of drilling fluids. The rheological profile of drilling fluids undergoes substantial changes when it flows into a wellbore. The complex nature of characterizing and predicting the rheological profile of drilling fluids is as a result of a combination of factors such as pressure, shear history, temperature and time (Abdo and Danish Haneef 2012; Ismail et al. 2016a, b; Vryzas et al. 2016). Precise estimation of the rheology of drilling fluids requires a good understanding of its properties and the impact of the associated microstructure on the flow behavior (Vryzas et al. 2015; Sehly et al. 2015). The fluid loss property of drilling fluids is another important property, which must be controlled for a cost-effective drilling campaign. This is seen as the second most important property after drilling fluid rheology. 

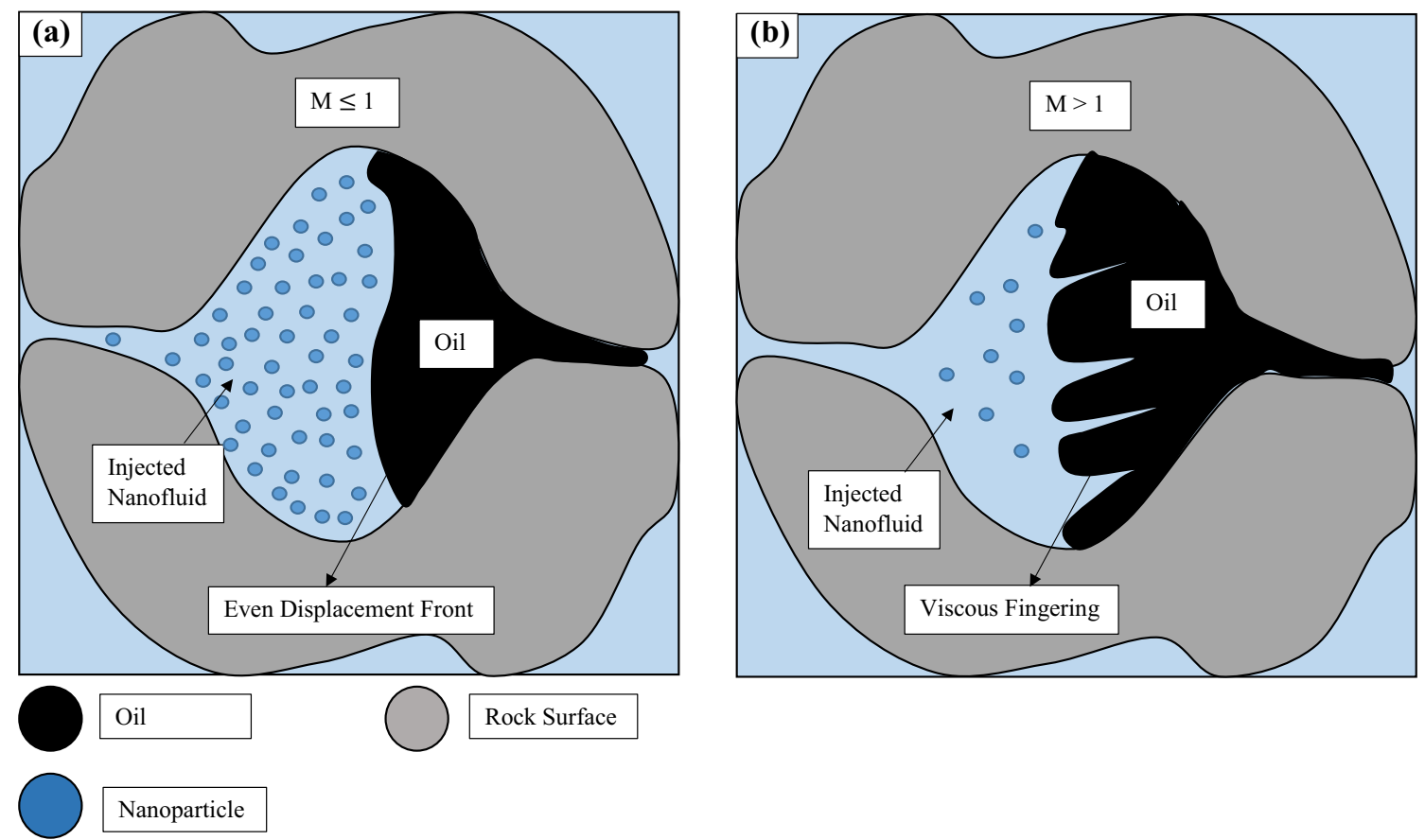

Fig. 3 Effect of nanoparticle concentration on the viscosity of the injected fluid a highly concentrated nanofluid gives an even displacement front $(M \leq 1)$. b Less concentrated nanofluid leads to an uneven displacement front (viscous fingering; $M>1$ )

Drilling fluid invasion into bare formations represents one of the key causes of formation damage. Such event may lead to expensive well stimulation activities and loss of production. The issue of fluid invasion into the exposed formation is known as a major factor responsible for the irregular decline in the productivity of most reservoirs (Aftab et al. 2016). The loss of fluids into bare formations takes place because of the pressure difference between the wellbore and the reservoir. This has necessitated the drilling of wells to be done as overbalanced, i.e., wellbore pressures being greater than the formation pressure. The loss of fluids into formations is accompanied by the deposition of solids from the drilling fluids on the face of the formation. The build-up of solids over time leads to the formation of a filter cake on the face of the formation. The filter cake is often impermeable and can help prevent excessive formation damage (Contreras et al. 2014). Various nanoparticles have been reported for use in rheology and fluid loss control of drilling fluids. Amanullah et al. (2011) reported test results on the formulation and application of three categories of nano-drilling fluids. The nano-based drilling fluids were homogenous and stable. The stability of the nanoparticles was ensured by the use of surfactants and polymers. The results from the test carried out on the nano-based drilling fluids showed that the fluid rheology was improved with high- and low-end rheological properties. Fluid loss was substantially reduced due to the formation of low permeable thin filter cake. With the reported results, the use of nanoparticles can be a good fluid loss additive and can reduce the incidence of differential pipe sticking in formations being drilled. Barry et al. (2015) evaluated the rheology and fluid loss behavior of bentonite suspensions using three nano-based additives; iron oxide nanoparticles, bentonite clay intercalated with iron oxide nanoparticles and alumina-silicate clay hybrid nanoparticles under high and low pressure and temperature conditions. Low conditions were set at $25{ }^{\circ} \mathrm{C}$ and $6.9 \mathrm{Bar}$ while high conditions were set at $200{ }^{\circ} \mathrm{C}$ and 70 Bar. The rheology and fluid loss behavior were affected by high conditions for temperature although the effect of pressure was insignificant compared to that of temperature. The shear stress values obtained for bentonite suspensions containing iron oxide nanoparticles and nanoparticle-intercalated clay were high at various shear rate compared to the base case suspension. The alumina-silicate hybrid gave low values for shear stress at varying shear rates when compared to the base case suspension. Fluid loss experiments under conditions of low temperature and pressure revealed a reduction in fluid loss by $37 \mathrm{vol} \%$ and $47 \mathrm{vol} \%$, respectively. This was obtained for bentonite clay intercalated with iron oxide nanoparticles and alumina-silicate clay hybrid nanoparticles when compared to the base case sample. The same nano-additives gave a reduction of $47 \mathrm{vol} \%$ under high pressure and temperature conditions. They explained that the reduction in the fluid loss by the iron oxide nanoparticles is due to the replacement of dissociated ions in the filter cake, thereby producing a low permeability medium. Furthermore, the performance of the 
other nano-additives can be explained in terms of the resilient-coagulated platelet and cross-linked network, which is less sensitive to temperature and pressure effects. This results in the formation of a less permeable filter cake, which brought about a reduction in fluid loss under conditions of low and high temperatures and pressures, respectively. This reduction in fluid loss was also explained in terms of the strong repulsive force between the clay platelets and the hybrid particles present in the structure. The modified surface structure of the formed filter cake was investigated using scanning electron microscope and zeta potential measurements. Mahmoud et al. (2016) examined the impact of a Ca-bentonite suspension containing iron oxide nanoparticles in reducing formation damage under high pressure and temperature conditions. The iron oxide nanoparticles have a significant effect on the rheology of the bentonite suspension at temperature up to $200{ }^{\circ} \mathrm{F}$ and pressure up to $300 \mathrm{psi}$. Aging test $\left(350^{\circ} \mathrm{F}, 16 \mathrm{~h}\right)$ performed on the bentonite suspension containing iron oxide nanoparticles revealed a stable suspension with little or no loss in its gel structure. The improved stability can be attributed to the interaction between the iron oxide nanoparticles and the bentonite clay particles. These interactions tend to enhance the gelation of the clay particles. The various rheological models applied to describe the rheology of the nanoparticle modified bentonite suspension indicated that the Herschel-Bulkley model best fits the rheological profile $\left(R^{2}=0.999\right)$. Fluid loss experiment under high pressure (300 psi) and temperature $\left(250^{\circ} \mathrm{F}\right)$ was performed using the OFITE high pressure and high-temperature filter press. Bentonite suspension containing $0.5 \mathrm{wt} \%$ iron oxide nanoparticles reduced the fluid loss by 42.7 vol\% when compared to the base bentonite suspension. The thickness of the corresponding filter cake was formed decreased by $17.32 \%$. Morphological study of the formed filter cake indicated that the surface is smooth with less aggregation as observed using SEM. It was concluded by the authors that iron oxide nanoparticles tend to improve the fluid loss behavior of bentonite suspensions. Zakaria et al. (2012) developed a set of nanoparticles as fluid loss additives for application in low permeable formations such as shale. The nanoparticles were applied to oil-based muds and tested using two approaches, in situ and ex situ. The rheological profile for drilling fluids containing the nanoparticles was observed at low shear rates to be non-linear. The profile under high shear rates approached linearity. This profile for nanoparticle modified drilling fluids is often due to the surface area and grain boundary of nanoparticles. The API fluid loss test revealed that $70 \mathrm{vol} \%$ decrease in the filtrate was attained when compared to $9 \mathrm{vol} \%$ achieved with conventional lost circulation materials. The filter cake obtained from the filtration experiment was thin, indicating a good potential in curbing the effects of differential pipe sticking. The use of silica nanoparticles as drilling fluid additive has also been reported. Mao et al. (2015) synthesized a polymer-based silica nanocomposite using inverse emulsion polymerization method with core-shell structure. Drilling fluids with the nanocomposite as additive showed good rheological and fluid loss properties, lubricating properties and thermal stability. $0.5 \mathrm{wt} \%$ of the nanocomposite reduced fluid loss by 69 vol\% under high temperature and pressure. It was concluded by the authors that the synthesized additive would ensure that formulated drilling fluids stabilize wellbore and protect reservoirs. Li et al. (2016) used silica nanoparticles along with potassium chloride $(\mathrm{KCl})$ and $\mathrm{XC}$ polymer as additives in the formulation of drilling fluids. The rheology of the drilling mud was improved while the filtrate achieved was reduced. The formed filter cake was thin which indicates good potential for reducing the occurrence of pipe sticking. The feasibility of using such modified drilling fluid was performed through cost analysis. Salih et al. (2016) also investigated the impact of silica nanoparticles on the fluid loss and rheology of water-based drilling fluids. The concentration of the silica nanoparticles ranged from $0.1 \mathrm{wt} \%$ to $0.3 \mathrm{wt} \%$. The nanoparticles had a significant impact on the rheology and fluid loss of the drilling fluids. Further observations were made that $\mathrm{pH}$ had a profound impact on the properties of the silica nanoparticle-modified drilling fluid. The authors established that the formulated drilling fluid has the prospect to substitute oil-based drilling fluid in directional, horizontal and shale drilling operations. Anoop et al. (2014) studied the rheological properties of mineral oil containing silica nanoparticles under high pressure and temperature conditions. The rheological profile of the tested sample was observed to follow a non-Newtonian behavior under high temperature and pressure. The viscosity of the fluid was observed to increase up to $100{ }^{\circ} \mathrm{C}$ with nanoparticle concentration beyond which there was a decrease in viscosity. The change in viscosity was attributed to chemical alteration between nanoparticles and the fluid particles as observed by infrared spectroscopy. The power law model was picked as the appropriate model, which described the rheology of the fluid based on statistical measures.

\section{Models for nano-drilling fluids}

Predicting the flow characteristics of drilling fluids would require that the rheological models meet certain specifications (Vipulanandan and Mohammed 2014):

$$
\begin{aligned}
& \tau=\tau_{0} \quad \text { when } \dot{\gamma}=0, \\
& \frac{\mathrm{d} \tau}{\mathrm{d} \dot{\gamma}}>0,
\end{aligned}
$$


$\frac{\mathrm{d}^{2} \tau}{\mathrm{d} \dot{\gamma}^{2}}<0$

$\tau=\tau_{\lim } \quad$ when $\dot{\gamma}=\infty$

where $\dot{\gamma}$ is the shear rate, $\tau$ is the shear stress, and $\tau_{0}$ is the yield stress. The first condition in Eq. (4) describes the viscous property called yield point, which plays an important role in the removal of drilled cuttings. The yield point of the drilling fluid affects the carrying capacity of the fluid and its ability to keep rock cuttings in suspension under dynamic and static conditions, respectively. The ability of drilling fluid to keep drill cuttings and weighting materials in suspension under dynamic conditions is dependent on its viscosity as described by Eq. (5). Without the viscous property, all the drill cuttings and weighting materials would settle at the bottom of the hole when circulation is stopped. Equation (6) describes the shear thinning characteristics of drilling fluids. Shear thinning is the non-Newtonian behavior of fluids whose viscosity decreases under increasing shear strain. Equation (7) describes the shear stress limit of the drilling fluid. This property has been described as a measure of the eroding capability of the drilling fluid. It is also a measure of the maximum shear stress tolerance of the drilling fluid. Reilly et al. (2016) and Gerogiorgis et al. (2017) developed multivariate shear stress model which described the rheological profile of drilling fluid containing iron oxide nanoparticles. The model for shear stress was developed using a first principle approach by considering microstructural assumptions. This was based on a force balance between the van der Waals attractions of monodispersed iron oxide nanoparticles. This characterizes the drilling fluid behavior as a function of shear rate, the volume fraction of nanoparticles and temperature. The developed model gave good agreement with experimental rheological data at high shear rates while discrepancies were observed at low shear rates. Equation (8) shows the governing expression used by the authors:

$\tau=\tau_{\mathrm{y}}+\tau_{\infty}+\tau_{\mathrm{p}}$,

where $\tau_{\mathrm{y}}$ is the yield stress, $\tau_{\infty}$ is the shear stress of the base fluid at infinite viscosity and $\tau_{\mathrm{p}}$ is the shear stress due to nanoparticles. The expression for the shear stress due to the nanoparticles was derived based on the assumptions:

a. The minimum inter-particle distance nanoparticles were assumed to be equivalent to four nanoparticle radii (Reilly et al. 2016; Gerogiorgis et al. 2017). This was chosen for the avoidance of nanoparticle aggregation or agglomeration.

b. The dispersion of nanoparticles in the bentonite suspension was assumed to follow a cubical arrangement. A cubic volume of the base fluid is assumed to contain a single nanoparticle (Masoumi et al. 2009).

Equation 9 shows the model developed by the authors:

$$
\tau(\gamma, \emptyset)=\tau_{\mathrm{y}}+\mu_{\infty} \gamma+\frac{A_{\mathrm{o}} r_{\mathrm{p}}}{12 A_{\mathrm{p}}\left[4 r_{\mathrm{p}}\left(\frac{1}{1+\beta \gamma}\right)+\left(1-\frac{1}{1+\beta \gamma}\right) d_{\mathrm{p}} \sqrt[3]{\frac{\pi}{6 \varnothing}}\right]^{2}},
$$

where $\mu_{\infty}$ represents the infinite shear rate viscosity and the term $\mu_{\infty} \gamma$ is the shear stress of the base fluid at this viscosity value. $\varnothing$ is the fractional volume of nanoparticles, $r_{\mathrm{np}}$ is the radius of nanoparticles, $d_{\mathrm{p}}$ is the diameter of nanoparticles and $A_{\mathrm{o}}$ is the Hamaker constant. The use of the infinite shear rate viscosity in evaluating the shear stress behaviour of the base fluid explains why the developed model by the authors gave good fit at high shear rates compared to low shear rates. According to Gerogiorgis et al. (2017), $\tau_{\infty}$ is the shear stress attributed to the constant viscosity of a suspension observed at high shear rates: this infinite viscosity is the observed plateau in shear-dependent viscosity. At infinite shear viscosity, the relationship between shear stress and shear rates can be approximated to follow a Bingham plastic behaviour. The model developed by the authors can be improved upon to capture drilling mud behaviour at low shear rates as well. This would involve looking at the structural behaviour of the drilling mud at low and high shear rates. The structural kinetics of cohesive suspensions as proposed by Toorman (1997) used a non-dimensional parameter as a measure in describing the degree of structure or cohesiveness in a sediment suspension. The value of the non-dimensional parameter is between 0 (for fully broken structure) and 1 (for fully structured bentonite suspension). The work of Reilly et al. (2016) and Gerogiorgis et al. (2017) laid a good foundation for rheological models for nano-drilling fluids but the authors did not consider extending the work to cover the fluid loss aspect of nano-drilling fluids. Applying their proposed model on inter-particle behaviour in colloidal suspensions and structural kinetics of Toorman (1997), a fluid loss model incorporating the effects nanoparticles can also be developed. This can also be extended to cover how nanoparticles affect the permeability of drilling mud cakes. Presently, there is no model which accounts for the fluid loss behaviour of nano-drilling fluids. The API fluid loss model simply represents a parametrized computation of fluid loss behaviour applied to nano-drilling fluids. The API fluid loss model has its limitations as identified by Vipulanandan et al. (2014). This includes constant value prediction for the mud cake permeability. In other words, the permeability of the mud cake remains constant with time. In addition, the ratio of solids on the mud cake to the solids in the drilling mud is assumed constant with the API model. Characterization of the behaviour of nano-drilling fluids based on shear rate,

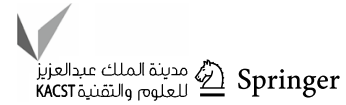


temperature and volume fraction of nanoparticles allows for economical and cost effective planning of drilling operations involving such drilling fluids. Furthermore, models such as Eq. (8), allow for prediction of the impact of the amount, type and size of nanoparticles on the profile of the rheology of the nano-drilling mud. Gerogiorgis et al. (2017) also investigated the effect of temperature on nano-drilling muds based on Eq. (9). A trivariate shear stress model (Eq. 10) was developed using an inverse an inverse exponential multiplier, $e^{\frac{C_{73}}{T}}$, for the temperature effect on base fluid viscosity and a linear multiplier, $C_{\tau 4} T+C_{\tau 5}$, for the nanoparticle induced shear stress effect. $C_{\tau 3}, C_{\tau 4}$, and $C_{\tau 5}$ are parameter constants, respectively, thermal conductivity of the drilling fluid increased further to about $31.8 \%$. For oil-based drilling fluids, the functionalized CNTs improved the thermal conductivity by $43.1 \%$ compared to $40.3 \%$ for the un-functionalized CNTs. William et al. (2014) investigated the impact of $\mathrm{ZnO}$ and $\mathrm{CuO}$ nanoparticles on the electrical and thermal conductivities of water-based drilling fluids. The size of the nanoparticles used was less than $50 \mathrm{~nm}$ and the base fluid use was $0.4 \mathrm{wt} \%$ xanthan gum solution. Drilling fluid formulated with $\mathrm{CuO}$ nanoparticles were observed to show enhanced thermal characteristics and resistant to high temperature $(25,70,90$ and $110^{\circ} \mathrm{C}$ ) and pressure (0.1-10 MPa) conditions than drilling fluids with $\mathrm{ZnO}$. The nanoparticles performed the task of

$A_{\mathrm{o}} r_{\mathrm{p}}$

$$
12 A_{\mathrm{p}}\left[4 r_{\mathrm{p}}\left(\frac{1}{1+\beta \gamma}\right)+\left(1-\frac{1}{1+\beta \gamma}\right) d_{\mathrm{p}} \sqrt[3]{\frac{\pi}{6 \varnothing}}\right]^{2}
$$

Reilly et al. (2016) developed a viscosity model incorporating the effect of nanoparticles as shown in (11). The model for viscosity was developed taking into account the force required to stabilize the nanoparticle in the suspension being equal to the drag force as estimated for the approximation of Stokes flow about a sphere: stabilizing the viscosity of the prepared drilling fluid at high temperatures. Ponmani et al. (2016) also studied the influence of $\mathrm{ZnO}$ and $\mathrm{CuO}$ nanoparticles with concentrations 0 $\mathrm{wt} \%-0.5 \mathrm{wt} \%$ dispersed in and polyvinylpyrrolidone (PVP), xanthan gum and polyethylene glycol (PEG-600) on thermal conductivity of drilling fluids. The nanoparticles used were

$\mu_{\text {app }}(\gamma, \emptyset, T)=\eta_{\infty}+\varphi\left(e^{-\frac{E}{R T}}\right) \frac{A}{72 \pi r_{\mathrm{p}} \gamma_{\mathrm{p}}\left[4 r_{\mathrm{p}}\left(\frac{1}{1+\beta \gamma}\right)+\left(1-\frac{1}{1+\beta \gamma}\right) d_{\mathrm{p}} \sqrt[3]{\frac{\pi}{6 \emptyset}}\right]^{2}}$

where $\varphi\left(e^{-\frac{E}{R T}}\right)$ represents an exponential multiplier (or

Arrhenius like) term, which takes into account the effect of temperature on the viscosity of the nano-drilling mud. $\varphi$ and $E$ represents the parameters, which were computed using regression analysis.

\section{Effect of nanoparticles on thermal behaviour of drilling fluids}

Frictional contact between the rock surface and the drill bit may lead to overheating of equipment and associated drilling problems which might impact directly on the cost and efficiency of drilling operations. Hence, the need for drilling fluids with exceptional heat transmission properties has become necessary as this will improve drilling operations. The heat transfer abilities of nanofluids are directly related to its thermal conductivity. Fazelabdolabadi et al. (2015) investigated the time evolution of thermal conductivity of drilling fluids containing functionalized CNTs. The thermal conductivity of the formulated drilling fluid was enhanced by $23.2 \%$ at $1 \mathrm{wt} \%$ functionalized CNTs. Variation of temperature from ambient conditions to about $50{ }^{\circ} \mathrm{C}$ saw the likened with micro-particles to investigate the impact of particle size. The nanoparticle-based drilling fluid showed better thermal conductivity compared with the micro-particle enhanced drilling fluid.

\section{Nanotechnology and flow assurance}

A common and costly problem in the oil and gas industry is that of corrosion and scale/wax formation. These two phenomena can inhibit the production system and bring about the obstruction of oil path during production, transportation, and refining (Bennetzen and Mogensen 2014). Scale formation occurs on the surface of the production line, around the wellbore, and in the porous formation enclosing the oil. Traditional methods such as squeeze treatments are often performed to curtail scale formation but are costly due to chemical cost and production loss arising from shut-in periods. Common techniques to solve this include scrapping and hot oil operation with the aid of coiled tubing unit (CTU) but this increase the non-productive time. 


\section{Corrosion inhibition of nanoparticles}

Carbon steel has turned out to be a significant part of life as a result of its widespread applications in petroleum and chemical industries, household appliances, construction industry, etc. Prevention of the corrosion phenomena is an age-old problem that exists in pipelines throughout the world. Atta et al. (2013) studied the corrosion inhibition efficiency of modified silver nanoparticles for carbon steel in $1 \mathrm{M}$ hydrochloric acid $(\mathrm{HCl})$. This was done by placing carbon steel in $\mathrm{HCl}$ solution of $1 \mathrm{M}$ concentration and the electrochemical impedance spectroscopy (EIS) technique was used for analysis. The inhibition efficiency of the nanoparticles was affected by the concentration of the nanoparticles. Increased concentration of nanoparticles tends to increase the inhibition efficiency of the nanoparticles with peak inhibition obtained at a concentration of $400 \mathrm{ppm}$. One of the benefits of scaling down is to reduce cost. The work of Atta et al. (2013) can be extended to look at optimizing inhibition efficiency while reducing the nanoparticle concentration through surface functionalization of the nanoparticles. By reducing nanoparticle concentration required to attain particular corrosion inhibition efficiency, the cost can be reduced.

\section{Wax/hydrate/asphaltene inhibition of nanoparticles}

Davidson et al. (2012) investigated a novel approach to inhibit the formation of wax on the solid surface through magnetically induced heating using superparamagnetic nanoparticles. The process of magnetically induced heating was described as "Neel Relaxation". The process used was similar to what was used in biomedicine heating and burning cancerous tissues. Experiments were carried out using superparamagnetic nanoparticles $(10 \mathrm{~nm})$ dispersed in water and hydrocarbon fluid. For solids, the nanoparticles were embedded in a solid film called "nanopoint". For a static fluid, the heat was generated in a linear proportion with the concentration of nanoparticles. It was also discovered that heat transfer from the nanopoint to the flowing fluid was three times greater compared to the static fluid. The suspension containing the superparamagnetic nanoparticles can be injected around the wellbore region and oil transportation pipelines. The application of the magnetically induced heating would reduce wax deposition or hydrate formation. Precipitation of asphaltene from crude oil can negatively affect crude oil production and transportation. This is can occur due to changes in pressure, temperature, and composition of the crude oil. Changes in composition often occur because of mixing of oil with injected solvent during EOR operations. It is therefore imperative to find an inhibitor, which can either prevent or delay the precipitation of asphaltene from crude oil. Mohammadi et al. (2011) investigated the effect of $\mathrm{TiO}_{2}, \mathrm{ZrO}_{2}$, and $\mathrm{SiO}_{2}$ fine nanoparticles potentially stabilizing asphaltene particles in the oil. The authors' titrated n-Heptane with dead oil samples obtained from Iranian oil reservoirs in the presence of the nanofluids. Polarized light microscopy was applied to determine the onset of asphaltene precipitation. It was discovered that $\mathrm{TiO}_{2}$ nanoparticles could only effectively prevent asphaltene precipitation under acidic conditions compared to basic conditions. Using FTIR spectroscopy, $\mathrm{TiO}_{2}$ nanoparticles prevented the precipitation of asphaltene through the formation of hydrogen bonds under acidic conditions. The other nanoparticles, $\mathrm{ZrO}_{2}$, and $\mathrm{SiO}_{2}$ were also observed to stabilize asphaltene nanoaggregates under acidic conditions through the formation of hydrogen bonds. Under basic conditions, the $\mathrm{ZrO}_{2}$, and $\mathrm{SiO}_{2}$ nanoparticles were unable to prevent the precipitation of asphaltene due to the inability to form hydrogen bonds. Nanoparticles prevent asphaltene precipitation through adsorption of the asphaltene molecules on its surface (Fig. 4). Asphaltene adsorption on nanoparticle surface has been reported to be affected by asphaltene content, temperature and contact time (Sun et al. 2017).

\section{Nanotechnology and reservoir characterization}

Subsurface applications of nanoparticles are not limited to drilling and oil recovery alone. There is also the use of nanoparticles in characterizing reservoir properties and heterogeneities. Bypassed oil can easily be identified using superparamagnetic nanoparticles as a contrast agent in an oil reservoir. This allows for the accurate determination of oil saturation in a reservoir (Avendano et al. 2012; Rahmani et al. 2015). Furthermore, the stability of the magnetic nanoparticles in suspension under high salinity and temperature is further enhanced through surface functionalization. The use of electromagnetic measurements can be used to track and monitor the injection of such nano-suspension in a reservoir over time. According to Bennetzen and Mogensen (2014), nanoparticles can be engineered to be stimuli-responsive based on reservoir conditions. Nanoparticles can be made to respond to changes in reservoir pressure and temperature, oil saturation, shear rate, etc. Agenet et al. (2012) examined the application of fluorescent gold-silica nanoparticle tracers for in situ real-time optical detection. The nanoparticles were engineered such that its size $(30-100 \mathrm{~nm})$ allowed for the encapsulation of glowing dyes, which forms the intrinsic signal of tracers and an interface with the environment for functionalization. The authors showed that the tracers based on fluorescent nanoparticles could act as sensitive probes of physicochemical state in terms of $\mathrm{pH}$, temperature, salt content, oil saturation, volume, etc., of an oil reservoir. The sensitivity of the prepared nanoparticles was due to their adaptability to monitoring setup, stability in conditions of high salinity, and their fluorescence coding.

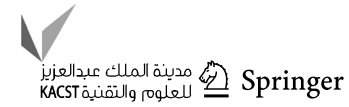



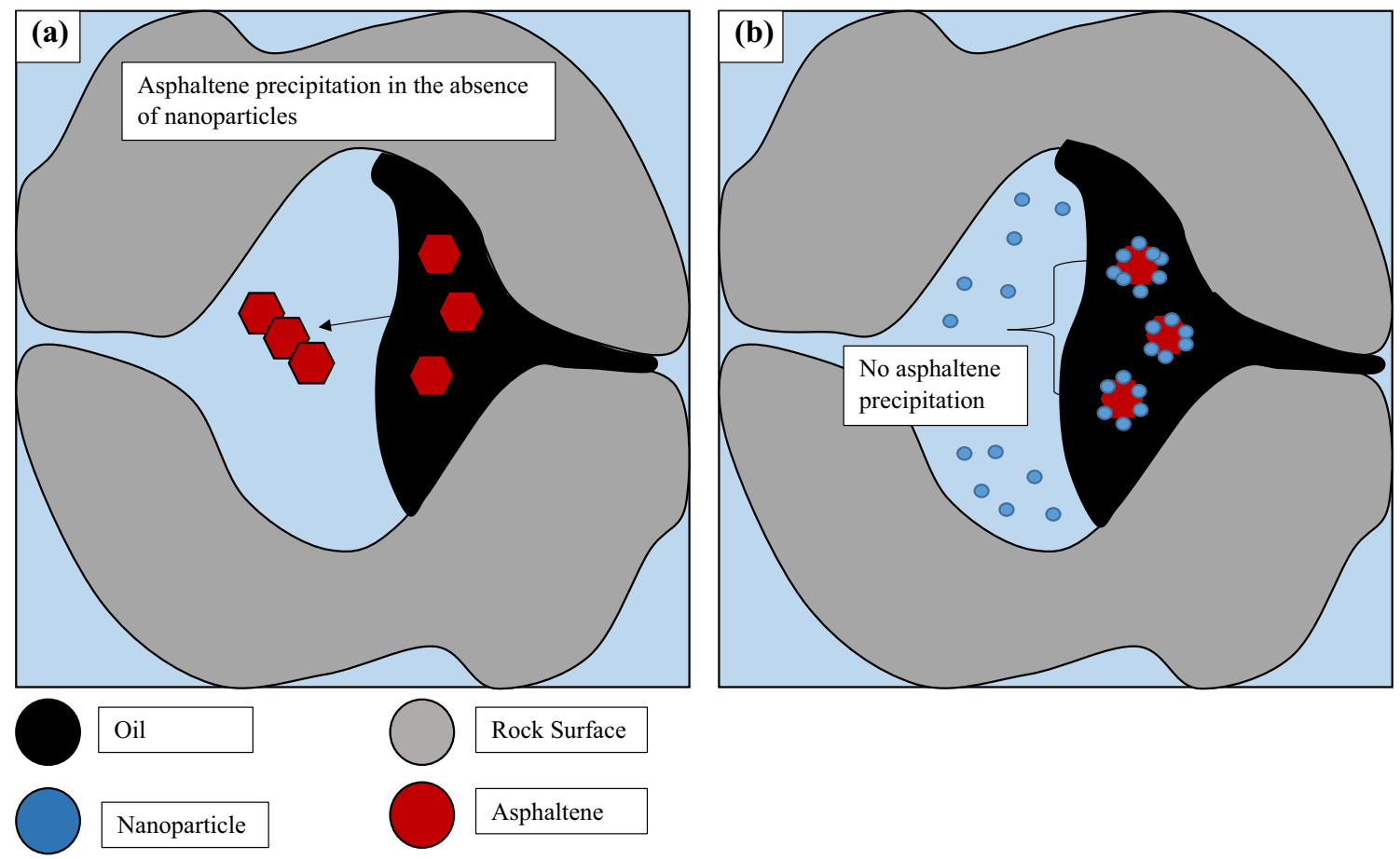

Fig. 4 Effect of nanoparticle in preventing asphaltene precipitation. a In the absence of nanoparticles. b In the presence of nanoparticles

The authors demonstrated the practical applicability of the fluorescent tracers through core flooding experiments with the easy propagation of nanoparticles and minor adsorption recorded. Rahmani et al. (2013) propagated stable suspensions of superparamagnetic nanoparticles in porous reservoir medium and investigated its response to a Croswell magnetic system. The authors used the underlying principle that the nanoparticles have the capability of changing the magnetic permeability of the flooded region, thereby enhancing the imaging of the flooding process. The consequence of this is the easy identification of reservoir heterogeneity through the illumination of flooded paths and fronts. The advantage of using such superparamagnetic nanoparticles compared to conventional tracers lies in the easy detection of the nanoparticles before breakthrough at the observatory well (Bennetzen and Mogensen 2014). Furthermore, the easy detection of the superparamagnetic nanoparticles makes real-time monitoring while chemical tracers have to be obtained from the reservoir and transported for laboratory analysis.

\section{Nanotechnology and challenges ahead for the oil and gas industry}

The research into the potential application of nanotechnology transcends every aspect of technological advancement (Subbiah et al. 2010; ShamsiJazeyi et al. 2014). Various challenges still exist and this has prevented the full application of nanotechnology in the oil and gas industry.

\section{Nanoparticle synthesis/production}

A key challenge, which has been identified among others towards the use of nanotechnology in the petroleum industry, relates to the production of nanomaterials. Large-scale production of nanomaterials for use in the industry is expensive going by conventional methods of synthesis. The expensive nature of nanoparticles can be related to the non-standardized approach to its production (Bennetzen and Mogensen 2014). An inexpensive and cheap procedure for nanoparticle production is vital for its field application in the oil and gas industry. As technology advances in the coming years, new and efficient approach would evolve towards nanoparticle production. The use of materials and resources domiciled in countries in providing solutions to challenges encountered in the petroleum industry has been encouraged by laws such as the local content act. This has stimulated increased research into potential application of agricultural waste in nanoparticle synthesis. The conventional physio-chemical procedures for large-scale nanoparticle production may be environmentally and economically undesirable (Kavitha et al. 2013; Logeswari et al. 2013). Therefore, the application of green nanotechnology in the petroleum industry could provide the cheap platform for nanomaterial synthesis and applications. The green synthesis of nanoparticles is dependent 
on a couple of factors which include: the nature of plant extract, the $\mathrm{pH}$ of the reaction medium, reaction temperature, electrochemical potential of metal ions in solutions, concentration of metal ions and the reaction time (Makarov et al. 2014). Makarov et al. (2014) described the mechanism describing the biological synthesis of metal nanoparticles as comprising of three major steps: activation phase, growth phase, and termination phase. In the activation phase, the metal ions in solution are reduced to metal atoms by the biologically active molecules in the plant extract after which the atom nucleation commence. In the growth phase, nanoparticles tend to coalesce into larger particles and this trend is often accompanied by increasing thermodynamic stability of the nanoparticles formed. The process by which nanoparticles coalesce into larger ones is known as "Ostwald Ripening". The termination phase is where the morphology of the nanoparticle is determined. This is largely dependent on the ability of the bio-molecules to stabilize the nanoparticles into the most energetically favorable conformation.

\section{Stability of nano-suspensions}

Besides this, other factors militate against the full application of nanomaterials. Among them is the chemical stability of nanofluids under harsh reservoir conditions. This affects the propagation of these nanoparticles in porous media. These factors are important when considering the application of nanoparticles for EOR. Moreover, research done so far in the area of "Nano-EOR" have shown that the field application of it might not be too far away but these few problems must be addressed for that to realized (Olatunde et al. 2012). The dispersibility of nanoparticles in a continuous medium is also paramount to drilling mud performance. For example, well-dispersed nanoparticles tend to effectively and efficiently carry out pore plugging capabilities, thereby ensuring wellbore and shale stability. When nanoparticles are not well dispersed, they tend to aggregate, thereby reducing their efficiency as an additive. Various equipment such as sonicator, homogenizer, and high shear mixers have been reportedly used in ensuring the dispersion of nanoparticles in various continuous media. After such high shearing with the equipment, the nanoparticle tends to aggregate after a given period of time due to the strong van der Waals force of attraction between them. Steric hindrance or repulsive forces is needed to overcome the force of attraction between the nanoparticles (Wen et al. 2009). The use of surfactants has been reported for use in stabilizing and dispersing nanoparticles in various continuous media (Salih et al. 2016).

\section{Predictive modelling of nanoparticle behavior}

Another key challenge involves attaining predictable properties for nanoparticle modified drilling mud. For example, the known rheological models used in the characterization of bentonite-based muds allow for a parameterized computation of fluid rheology (Vryzas and Kelessidis 2017). In other words, such models cannot quantitatively capture the contributions of nanoparticles to the overall fluid rheology of the modified bentonite mud. In such approach, shear stress and viscosity are expressed as a data-driven correlation or explicit function of shear rate. The work of Reilly et al. (2016) and Gerogiorgis et al. (2017) laid a good foundation for rheological models for nano-drilling fluids, Furthermore, extending the work to cover other aspects of drilling mud performance such as fluid loss behavior is important. There is currently no known model which describes the fluid loss behavior of nano-drilling muds. The development of models for describing the fluid behavior of nanoparticleenhanced drilling fluids is critical towards successful modelling, design and cost-effective drilling operations. The well-known API fluid loss model is simply a function of time and parametrized approach is taken when describing the fluid loss of nanoparticle-enhanced drilling fluids. The contributory effect of nanoparticles in the fluid loss reduction is not captured in the model.

\section{Aversion to new technologies}

Getting oil companies to embrace new technologies such as nanotechnology is becoming challenging. Most companies are risk-averse in the event of a crash in the price of crude oil in the global market. The recent crash of crude oil price in 2014 had far-reaching consequences on the output of many oil and gas operators. This has made new projects more costly, economically and technically challenging as the availability of sufficient funds for research and development becomes less available. Moreover, most operators may contemplate the use of new technology a riskier proposal than the established technologies in use. The gradual increase in the price of crude oil after the crash of 2014 may change the risk averseness of oil and gas operators towards the adoption of new technologies such as nanotechnology (Bennetzen and Mogensen 2014).

\section{Recommendations for future research}

Based on the findings of this work, the following are recommended for future research:

a. Investigation of nanoparticle retention on rock surfaces during core flooding. This would require the determination of nanoparticle concentration before injection and the concentration of nanoparticles in the ejected effluent fluid. Furthermore, the retention of nanoparticles and

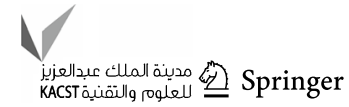


its effect on rock properties (permeability and porosity) should be investigated for different rock types.

b. Investigation into the use of "Nanofluid Slugs" for residual oil mobilization should be carried out (Torsater et al. 2012). Nanofluid slugs can be obtained through alternating brine and nanofluid injection into oil-saturated core sample. The brine could help reduce the effect of nanoparticle adsorption on rock surface, as the presence of salts will desorb retained nanoparticles on the rock surface. This process may provide a possible solution porosity/permeability impairment attributed to the use of nanoparticles. Another possible advantage of this lies in the reduction of nanoparticles employed compared to a continuous injection of nanofluids.

c. There is also need to investigate the relationship between nanoparticle size/morphology and recovery rate for different injection rates (Torsater et al. 2012). The propagation of nanoparticles in porous media is function of its size variation. The morphology or shape of nanoparticles is also a key in its propagation. A good understanding of the relationship between nanoparticle size/morphology and recovery rate for different injection rates would help in proper computation of pumping requirements for nano-EOR process.

d. In addition, the relationship between nanoparticle size/ morphology and rheological properties of drilling muds should be investigated. The size and morphology of the nanoparticles employed in drilling mud formulation may impact on the force of attraction between the nanoparticles and the bentonite clay particles.

e. A combination of low salinity waterflooding with nanoparticles can also be investigated for different concentrations of salt. The impact of varied salt concentration on the ability of the nanoparticles in reducing interfacial tension and wettability alteration would be significant.

f. Predictive models for rock permeability/porosity impairment by nanoparticles are important for computational modelling, economical and cost effective planning of EOR operations involving nanoparticles. Besides permeability/porosity impairment, a correlative model that relates oil recovery to different oil, rock and nanoparticle properties would be hugely significant for the potential application of nano-EOR.

g. A predictive fluid loss model for drilling muds incorporating the effects nanoparticles based on size, volume concentration and type is required. This can be extended to cover how nanoparticles affect the permeability of drilling mud cakes. Presently, there is no model, which accounts for the fluid loss behaviour of nano-drilling fluids. The API fluid loss model simply represents a parametrized computation of fluid loss behaviour is applied to nano-drilling fluids.

\section{Conclusion}

The prospect for a paradigm shift towards the application of nanotechnology in the oil and gas industry is constrained by evolving challenges with its progression. The oil and gas industry over the past decade have witnessed increased research into the use of nanotechnology with great potential for drilling operations, EOR, reservoir characterization, production, etc. This paper gave detailed review of works on nanotechnology based on the following:

- Enhanced oil recovery (EOR).

- Drilling mud technology.

- Production/flow assurance.

- Reservoir characterization.

The key findings from nano-research in the oil and gas industry have revealed the potential inherent in a nanoindustry. Moreover, opportunities and challenges were discussed and a note on a design framework for future research described.

Acknowledgements The authors would like to appreciate the management of Covenant University for providing an enabling environment to carry out this research.

Funding A specific grant from funding agencies in the public, commercial, or not-for-profit sectors was not received for this research work.

\section{Compliance with ethical standards}

Conflict of interest The authors have no conflict of interest to declare.

Open Access This article is distributed under the terms of the Creative Commons Attribution 4.0 International License (http://creativeco mmons.org/licenses/by/4.0/), which permits unrestricted use, distribution, and reproduction in any medium, provided you give appropriate credit to the original author(s) and the source, provide a link to the Creative Commons license, and indicate if changes were made.

\section{References}

Abdo J, Danish Haneef M (2012) Nano-enhanced drilling fluids: pioneering approach to overcome uncompromising drilling problems. J Energy Res Technol 134:1-6

Afolabi RO, Orodu OD, Efeovbokhan VE (2017a) Properties and application of Nigerian bentonite clay deposits for drilling mud formulation: recent advances and future prospects. Appl Clay Sci 143:39-49

Afolabi RO, Orodu OD, Efeovbokhan VE, Rotimi OJ (2017b) Optimizing the rheological properties of silica nano-modified bentonite mud using overlaid contour plot and estimation of maximum or upper shear stress limit. Cogent Eng 4:1-18

Aftab A, Ismail AR, Khokhar S, Ibupoto ZH (2016) Novel zinc oxide nanoparticles deposited acrylamide composite used for enhancing 
the performance of water-based drilling fluids at elevated temperature conditions. J Pet Sci Eng 146:1142-1157

Agenet N, Perriat P, Brichart T, Crowther N, Martini M, Tillement O (2012) Fluorescent nanobeads: a first step toward intelligent water tracers. In: SPE international oilfield nanotechnology conference and exhibition. Society of Petroleum Engineers, Noordwijk, pp 1-13

Al-Anssari S, Barifcani A, Wang S, Maxim L, Iglauer S (2016) Wettability alteration of oil-wet carbonate by silica nanofluid. J Colloid Interface Sci 461:435-442

Alomair OA, Matar KM, Alsaeed YH (2014) Nanofluids application for heavy oil recovery. In: SPE Asia Pacific Oil \& Gas Conference and Exhibition, Adelaide, Australia, 14-16 October 2014

Amanullah M, Al-Arfaj MK, Al-Abdullatif ZA (2011) Preliminary test results of nano-based drilling fluids for oil and gas field application. In: SPE/IADC conference and exhibition. Society of Petroleum Engineers, Amsterdam

Anoop K, Sadr R, Al-Jubouri M, Amani M (2014) Rheology of mineral oil- $\mathrm{SiO}_{2}$ nanofluids at high pressure and high temperature. Int $\mathrm{J}$ Therm Sci 77:108-115

Atta AM, El-Mahdy GA, Al-Lohedan HA (2013) Corrosion inhibition efficiency of modified silver nanoparticles for carbon steel in $1 \mathrm{M}$ $\mathrm{HCl}$. Int J Electrochem Sci 8:4873-4885

Avendano C, Lee SS, Escalera G, Colvin V (2012) Magnetic characterization of nanoparticles designed for use as contrast agents for downhole measurements. In: SPE international oilfield nanotechnology conference and exhibition. Society of Petroleum Engineers, Noordwijk, pp 1-5

Barry MM, Jung Y, Lee JK, Phuoc TX (2015) Fluid filtration and rheological properties of nanoparticle additive and intercalated clay hybrid bentonite drilling fluids. J Pet Sci Eng 127:338-346

Bennetzen MV, Mogensen K (2014) Novel applications of nanoparticles for future enhanced oil recovery. In: International petroleum technology conference. Society of Petroleum Engineers, Kuala Lumpur, pp 1-14

Contreras O, Hareland G, Husein M, Nygaard R, Mortadha A (2014) Application of in-house prepared nanoparticles as filtration control additive to reduce formation damage. In: SPE international symposium and exhibition on formation damage control. Society of Petroleum Engineers, Lafayette

Davidson A, Huh C, Lawrence S (2012) Focused magnetic heating utilizing superparamagnetic nanoparticles for improved oil production. In: SPE international oilfield nanotechnology conference and exhibition. Society of Petroleum Engineers, Noordwijk, pp 1-16

El-Diasty AI (2015) The potential of nanoparticles to improve oil recovery in bahariya formation, Egypt: an experimental study. In: SPE Asia Pacific Enhanced Oil Recovery Conference, Kuala Lumpur, Malaysia, 11-13 August 2015

Ehtesabi H, Ahadian MM, Taghikhani V (2014) Enhanced heavy oil recovery using $\mathrm{TiO} 2$ nanoparticles: Investigation of deposition during transport in core plug. Energy and Fuels 29:1-8

Fazelabdolabadi B, Khodadadi AA, Sedaghatzadeh M (2015) Thermal and rheological properties improvement of drilling fluids using functionalized carbon nanotubes. Appl Nanosci 5:651-659

Giraldo J, Benjumea P, Lopera S, Cortes FB, Ruiz MA (2013) Wettability alteration of sandstone cores by alumina-based nanofluids. Energy and Fuels 27:3659-3665

Gerogiorgis DI, Reilly S, Vryzas Z, Kelessidis VC (2017) Experimentally validated first-principles multivariate modeling for rheological study and design of complex drilling nanofluid systems. In: SPE/IADC drilling conference and exhibition. Society of Petroleum Engineers, Hague, pp 1-11

Haroun MR, Alhassan S, Ansari AA, Kindy NAM, Sayed NA, Kareem BAA, Sarma HK (2012) Smart nano-EOR process for abu dhabi carbonate reservoirs. In: Abu Dhabi International Petroleum
Conference and Exhibition, Abu Dhabi, UAE, 11-14 November 2012

Hendraningrat L, Torsæter O (2014) Understanding fluid-fluid and fluid-rock interactions in the presence of hydrophilic nanoparticles at various conditions. In: SPE Asia Pacific Oil \& Gas Conference and Exhibition, Adelaide, Australia, 14-16 October 2014

Hendraningra L, Li S, Torsater O (2013) Effect of some parameters influencing enhanced oil recovery process using silica nanoparticles: an experimental investigation. In: SPE Reservoir Characterization and Simulation Conference and Exhibition, Abu Dhabi, UAE, 16-18 September 2013

Hoelscher KP, Stefano G, Riley M, Young S (2012) Application of nanotechnology in drilling fluids. In: SPE international oilfield nanotechnology conference. Society of Petroleum Engineers, Noordwijk, pp 1-7

Ismail AR, Aftab A, Ibupoto ZH, Zolkifile N (2016a) The novel approach for the enhancement of rheological properties of water based drilling fluids using multi-walled carbon nanotubes, nanosilica and glass beads. J Pet Sci Eng 139:264-275

Ismail AR, Aftab A, Ibupoto ZH, Zolkifile N (2016b) The novel approach for the enhancement of rheological properties of waterbased drilling fluids by using multi-walled carbon nanotube, nanosilica and glass beads. J Pet Sci Eng 139:264-275

Jung CM, Zhang R, Chenevert M, Sharma M (2013) High performance water-based mud using nanoparticles for shale reservoirs. In: Unconventional resources technology conference. Society of Petroleum Engineers, Denver, pp 1-7

Kavitha KS, Baker S, Rakshith D, Kavitha HU, Yashwantha Rao HC, Harini BP, Satish S (2013) Plants as green source towards synthesis of nanoparticles. Int Res J Biol Sci 2(6):66-76

Kazemzadeh Y, Eshraghi SE, Kazemi K, Sourani S, Mehrabi M, Ahmadi Y (2015) Behavior of asphaltene adsorption onto the metal oxide nanoparticle surface and its effect on heavy oil recovery. Ind Eng Chem Res 54:233-239

Karimi A, Fakhroueian Z, Bahramian A, Khiabani NP, Darabad JB, Aniz R, Arya S (2012) Wettability alteration in carbonates using zirconium oxide nanofluids: EOR implications. Energy and Fuels $26: 1028-1036$

Li S, Osisanya S, Haroun M (2016) Development of new smart drilling fluids using nano-materials for unconventional reservoirs. In: Abu Dhabi international petroleum exhibition \& conference. Society of Petroleum Engineers, Abu Dhabi

Li S, Hendraningrat L, Torsaeter O (2013) Improved oil recovery by hydrophilic silica nanoparticles suspension: 2 phase flow experimental studies. In: International Petroleum Technology Conference. European Association of Geoscientists \& Engineers, Beijing, China, 26-28 March 2013

Li S, Genys M, Wang K, Trosaeter O (2015) Experimental study of wettability alteration during nanofluid enhanced oil recovery process and its effect on oil recovery. In: SPE Reservoir Characterisation and Simulation Conference and Exhibition, Abu Dhabi, UAE, 14-16 September 2015

Logeswari P, Silambarasan S, Abraham J (2013) Ecofriendly synthesis of silver nanoparticles from commercially available plant powder and their anti-bacterial properties. Scientia Iranica $F$ 20(3):1049-1054

Mahmoud O, Nazr El-Din N, Vryzas Z, Kelessidis V (2016) Nanoparticle based drilling fluids for minimizing formation damage in HP/ HT applications. In: SPE international conference and exhibition on formation damage and control. Society of Petroleum Engineers, Louisiana, pp 1-26

Makarov VV, Love AJ, Sinitsyna OV, Makarova SS, Yaminsky IV, Taliansky ME, Kalinina NO (2014) "Green" nanotechnologies: synthesis of metal nanoparticles using plants. Acta Naturae 6(1):35-44

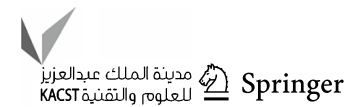


Maghzi A, Mohammadi S, Ghazanfari MH, Kharrat R, Masihi M (2012) Monitoring wettability alteration by silica nanoparticles during water flooding to heavy oils in five-spot systems: A porelevel investigation. Exp Therm Fluid Sci 40:168-176

Mao H, Qiu Z, Shen Z, Huang W, Zhong H, Dai W (2015) Novel hydrophobic associated polymer based nano-silica composite with core-shell structure for intelligent drilling fluid under ultra-high temperature and ultra-high pressure. Prog Nat Sci Mater 25:90-93

Masoumi N, Sohrabi N, Behzadmehr A (2009) A new model for calculating the effective viscosity of nanofluids. J Phys D Appl Phys 42:1-6

Miranda CR, De Lara LS, Tonetto BC (2012) Stability and mobility of functionalized silica nanoparticles for enhanced oil recovery applications. In: SPE international oilfield nanotechnology conference and exhibition. Society of Petroleum Engineers, Noordwijk, pp 1-11

Mohammadi M, Akbari M, Fakhroueian Z, Bahramian A, Azin R, Arya $\mathrm{S}$ (2011) Inhibition of asphaltene precipitation by $\mathrm{TiO}_{2}, \mathrm{SiO}_{2}$, and $\mathrm{ZrO}_{2}$ nanofluids. Energy Fuels 25(7):3150-3156

Mohebbifar M, Ghazanfari MH, Vossoughi M (2015) Experimental investigation of nano-biomaterial applications for heavy oil recovery in shaly porous models: A pore-level study. J Energy Resour Technol 137:1-7

Ogolo NA, Olafuyi OA, Onyekonwu MO (2012) Enhanced oil recovery using nanoparticles. In: SPE Saudi Arabia section technical symposium and exhibition. Society of Petroleum Engineers, AlKhobar, pp 1-9

Olatunde AO, Usman MA, Olafadehan OA, Adeosun TA, Ufot OE (2012) Improvement of rheological properties of drilling fluids using locally based materials. Pet Coal 54(1):65-75

Onyekonwu MO, Ogolo NA (2010) Investigating the use of nanoparticles in enhancing oil recovery. In: Nigeria annual international conference and exhibition. Society of Petroleum Engineers, Calabar, pp 1-14

Ponmani S, Nagarajan R, Sangwai JS (2016) Effect of nanofluids of $\mathrm{CuO}$ and $\mathrm{ZnO}$ in polyethylene glycol and polyvinylpyrrolidone on the thermal, electrical, and filtration-loss properties of waterbased drilling fluids. SPE J 21:405-415

Ragab AM, Hannora AE (2015) A Comparative investigation of nano particle effects for improved oil recovery-experimental work. In: SPE Kuwait Oil and Gas Show and Conference, Mishref, Kuwait, 11-14 October 2015

Rahmani AR, Bryant S, Huh C, Athey A, Ahmadian M, Chen J, Wilt M (2013) Crosswell magnetic sensing of superparamagnetic nanoparticles for subsurface applications. In: SPE annual technical conference and exhibition. Society of Petroleum Engineers, New Orleans, pp 1-16

Rahmani AR, Bryant SL, Huh C, Ahmadian M, Zhang W, Liu QH (2015) Characterizing reservoir heterogeneities using magnetic nanoparticles. In: SPE reservoir simulation symposium. Society of Petroleum Engineers, Houston, pp 1-29

Reilly S, Vryzas Z, Kelessidis VC, Gerogiorgis DI (2016) First principles rheological modelling and parameter estimation for nanoparticle based smart drilling fluids. In: European symposium on computer aided process engineering. Elsevier B. V., Portoroz, pp 1-6

Roustaei A, Barzagadeh $\mathrm{H}$ (2015) Experimental investigation of $\mathrm{SiO}_{2}$ nanoparticles on enhanced oil recovery of carbonate reservoirs. J Pet Explor Prod Technol 5(1):27-33. https://doi.org/10.1007/ s13202-014-0120-3

Roustaei A, Moghadasi J, Bagherzadeh H, Shahrabadi A (2012) An experimental investigation of polysilicon nanoparticles' recovery efficiencies through changes in interfacial tension and wettability alteration. In: SPE international oilfield nanotechnology conference and exhibition. Society of Petroleum Engineers, Noordwijk, pp 1-7. https://doi.org/10.2118/156976-MS
Roustaei A, Saffarzadeh S, Mohammadi M (2013) An evaluation of modified silica nanoparticles' efficiency in enhancing oil recovery of light and intermediate oil reservoirs. Egypt J Pet 22(3):427433. https://doi.org/10.1016/j.ejpe.2013.06.010

Roustaei A, Bagherzadeh H (2015) Experimental investigation of $\mathrm{SiO} 2$ nanoparticles on enhanced oilrecovery of carbonate reservoirs. J Pet Explor Prod Technol 5:27-33

Sadeghalvaad M, Sabbaghi S (2015) The effect of the $\mathrm{TiO}_{2}$ /polyacrylamide nanocomposite on water-based drilling fluid properties. Powder Technol 272:113-119

Salih AH, Elshehabi TA, Bilgesu HI (2016) Impact of nanomaterials on the rheological and filtration properties of water-based drilling fluids. In: SPE eastern regional meeting. Society of Petroleum Engineers, Canton

Sehly K, Chiew H-L, Li H, Song A, Leong Y, Huang W (2015) Stability and aging behaviour and the formulation of potassium based drilling muds. Appl Clay Sci 104:309-317

Shah RD (2009) Application of nanoparticle saturated injectant gases for EOR of heavy oils. In: SPE annual technical conference and exhibition. Society of Petroleum Engineers, New Orleans

ShamsiJazeyi H, Miller CA, Wong MS, Tour JM, Verduzco R (2014) Polymer-coated nanoparticles for enhanced oil recovery. J Appl Polym Sci 131(15):1-13. https://doi.org/10.1002/app.40576

Subbiah R, Veerapandian M, Yun KS (2010) Nanoparticles: functionalization and multifunctional applications in biomedical sciences. Curr Med Chem 17(35):4559-4577. https://doi. org/10.2174/092986710794183024

Sun X, Zhang Y, Chen G, Gai Z (2017) Application of nanoparticles in enhanced oil recovery: a critical review of recent progress. Energies 10(345):1-33

Son H, Kim H, Lee G, Kim J, Sung W (2014) Enhanced oil recovery using nanoparticle-stabilized oil/water emulsions. Korean J Chem Eng 31(2):338-342

Tarek M (2015) Investigating nano-fluid mixture effects to enhance oil recovery. In: SPE Annual Technical Conference and Exhibition, Houston, TX, USA, 28-30 September 2015

Tarek M, El-Banbi AH (2015) Comprehensive investigation of effects of nano-fluid mixtures to enhance oil recovery. In: SPE North Africa Technical Conference and Exhibition, Cairo, Egypt, 14-16 September 2015

Torsater O, Engeset B, Hendraningrat L, Suwanro S (2012) Improved oil recovery by nanofluids flooding: an experimental study. In: SPE Kuwait International Petroleum Conference and Exhibition, Kuwait City, Kuwait, 10-12 December 2012

Toorman EA (1997) Modelling the thixotropic behaviour of dense cohesive sediment suspensions. Rheol Acta 36(1):56-65

Vipulanandan C, Mohammed AS (2014) Hyperbolic rheological model with shear stress limit for acrylamide polymer modified bentonite drilling muds. J Pet Sci Eng 122:38-47

Vryzas Z, Kelessidis VC (2017) Nano-based drilling fluids: a review. Energies 10:1-34

Vryzas Z, Mahmoud O, Nasr-El-Din HA, Kelessidis VC (2015) Development and testing of novel drilling fluids using $\mathrm{Fe}_{2} \mathrm{O}_{3}$ and $\mathrm{SiO}_{2}$ nanoparticles for enhanced drilling operations. In: International petroleum technology conference. Doha: Society of Petroleum Engineers, pp 1-18

Vryzas Z, Wubulikasimu Y, Gerogiorgis D, Kelessidis VC (2016) Understanding the temperature effect on the rheology of waterbentonite suspensions. Nordic Polymer Days and Nordic Rheological Conference, Helsinki

Wen D, Lin G, Vafaei S, Zhang K (2009) Review of nanofluids for heat transfer applications. Particuology 7:41-150

William JM, Ponmani S, Samuel R, Nagarajan R, Sangwai JS (2014) Effect of $\mathrm{CuO}$ and $\mathrm{ZnO}$ nanofluids in xanthan gum on the thermal, electrical and high pressure rheology of water based drilling fluids. J Pet Sci Eng 117:15-27 
Yu J, Berlin JM, Lu W, Zhang L, Kan AT, Zhang P, Tomson MB (2010) Transport study of nanoparticles for oil field application. In: SPE international conference on oilfield scale. Society of Petroleum Engineers, Aberdeen, pp 1-16

Zakaria MF, Husein M, Harelamnd G (2012) Novel nanoparticle-based drilling fluid with improved characteristics. In: SPE international oilfield nanotechnology conference. Society of Petroleum Engineers, Noordwijk, pp 1-6
Publisher's Note Springer Nature remains neutral with regard to jurisdictional claims in published maps and institutional affiliations. 